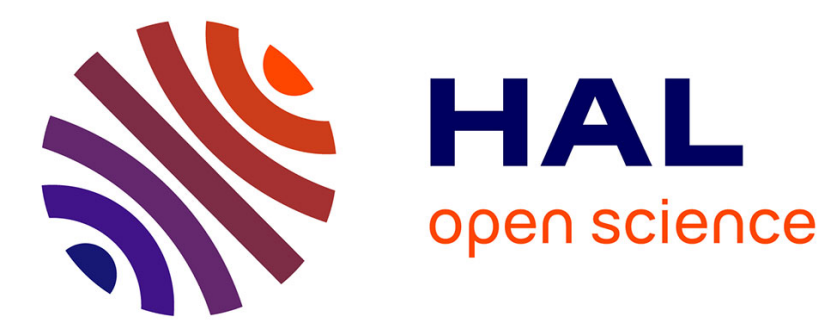

\title{
Plasma in photon matter interaction during laser material processing
}

\author{
R. Fabbro, A. Poueyo
}

\section{To cite this version:}

R. Fabbro, A. Poueyo. Plasma in photon matter interaction during laser material processing. Journal de Physique IV Proceedings, 1994, 04 (C4), pp.C4-3-C4-8. 10.1051/jp4:1994401 · jpa-00252539

HAL Id: jpa-00252539

https://hal.science/jpa-00252539

Submitted on 1 Jan 1994

HAL is a multi-disciplinary open access archive for the deposit and dissemination of scientific research documents, whether they are published or not. The documents may come from teaching and research institutions in France or abroad, or from public or private research centers.
L'archive ouverte pluridisciplinaire HAL, est destinée au dépôt et à la diffusion de documents scientifiques de niveau recherche, publiés ou non, émanant des établissements d'enseignement et de recherche français ou étrangers, des laboratoires publics ou privés. 


\title{
Plasma in photon matter interaction during laser material processing
}

\author{
R. FABBRO and A. POUEYO
}

L.A.L.P., Laboratoire d'Application des Lasers de Puissance, Unité Mixte ETCA/CNRS, 16 bis Avenue Prieur de la Côte d'Or, 94114 Arcueil cedex, France

\section{INTRODUCTION}

Plasma state is always present in several processes which require very high densities of energy : this is the case in pulse processing mode where, for nanoseconds pulse durations, intensities of several $\mathrm{GW} / \mathrm{cm}^{2}$ are required. For $\mathrm{CW}$ processing, these phenomena occurs for intensities in the $M W / \mathrm{cm}^{2}$ range. This is the case of the welding process. Even if this process has been used for industrial application quite since the begining of the laser, the precise role of this plasma is not completely understood during this process. We propose in this paper to give some new insigths in this field. In a first part, we will recall basic principles of plasma generation ; a second part is devoted to some experimental results on its characterization in the plume and inside the keyhole.

1) Basic principle of plasma generation.

The evolution of the electronic density in a gas irradiated by a laser with an intensity I can be easily described by a set a coupled rate equations describing the electronic density Ne and mean energy $\bar{\varepsilon}\{1\}$ :

$$
\frac{\mathrm{dNe}}{\mathrm{dt}}=\mathrm{R}_{\mathbf{i}}-\text { Rloss } \quad \text { et } \mathrm{Ne} \frac{\mathrm{d} \bar{\varepsilon}}{\mathrm{dt}}=\alpha I-\mathrm{Pel}_{\mathrm{e}}-\text { Ploss }
$$

where $R_{\mathbf{i}}$ and $\mathrm{R}_{\text {loss }}$ are ionisation and loss rates (by diffusion or recombination), Pel and Ploss, the elastic and inelastic losses of energy and $\alpha$ the Inverse Bremsstralhung (I. B.) absorption coefficient given by :

$$
\alpha \approx \frac{v \omega^{2} p}{c\left(v^{2}+\omega^{2}\right)}
$$

where $v, \omega p$ and $\omega$ are respectively the electronic collision, plasma and laser frequencies. Resolution of equ. (1) show that for a typical laser intensity of about 1 $\mathrm{MW} / \mathrm{cm}^{2}$, Ne and $\bar{\varepsilon}$ reaches values of about $10^{17} \mathrm{~cm}^{-3}$ and $1 \mathrm{eV}$ in a few $\mu \mathrm{s}$. It is interesting to note that this breakdown process of the gas occurs, only if the laser intensity is greater than an intensity threshold $\mathrm{I}_{i}$ given by $\{2\}$ :

$$
\mathrm{I}_{\mathrm{i}}\left(\mathrm{MW} / \mathrm{cm}^{2}\right) \approx 600 \frac{\Delta(\mathrm{eV})}{\lambda^{2}(\mu \mathrm{m}) \mathrm{A}}
$$

where $\Delta, \lambda$ and $A$ are respectively the ionisation energy and the atomic mass of the atom gas, and the laser wavelenght. The effect of each of these parameters in this criterion is obvious, and it shows that, for $\mathrm{CO}_{2}$ lasers for example, $\mathrm{I}_{\mathrm{i}}$ is rather low for the usual processed metals $\left(I_{i} \approx 0.8 \mathrm{MW} / \mathrm{cm}^{2}\right.$ for iron); As the evaporation intensity of metals is lower (for practical processing speeds), this means that with a $\mathrm{CO}_{2}$ laser, the metallic vapour is always ionised. The ionisation of the protective gases usually used in welding occurs for higher intensities. Only helium cannot be ionised with laser intensities used during welding. Moreover, we can also show that the characteristic time $\tau$ of plasma breakdown scales as $\lambda^{-2} I^{-3}\{3\}$. All these considerations show the important consequences of using shorter wavelenghts than the $\mathrm{CO}_{2}$ one on plasma generation : it makes this production more difficult by increasing the threshold laser intensity and its growth time. Now, let's study the effect of the plasma on laser propagation. 
2) Experimental study of plasmas under welding conditions.

If one wants to know the effect of plasmas, one has first to determine their microscopic parameters, such as electronic density and temperature, in order to estimate their macroscopic effect on laser beam absorption or refraction. The experimental techniques used for these measurements based on spectroscopy (line intensity ratio or Stark broadening) are described in details in ref. \{4-5\}. Examples of electronic density and temperature profiles above a target obtained for 2 conditions of laser intensities with an He protecting gas, are shown in fig. 1.
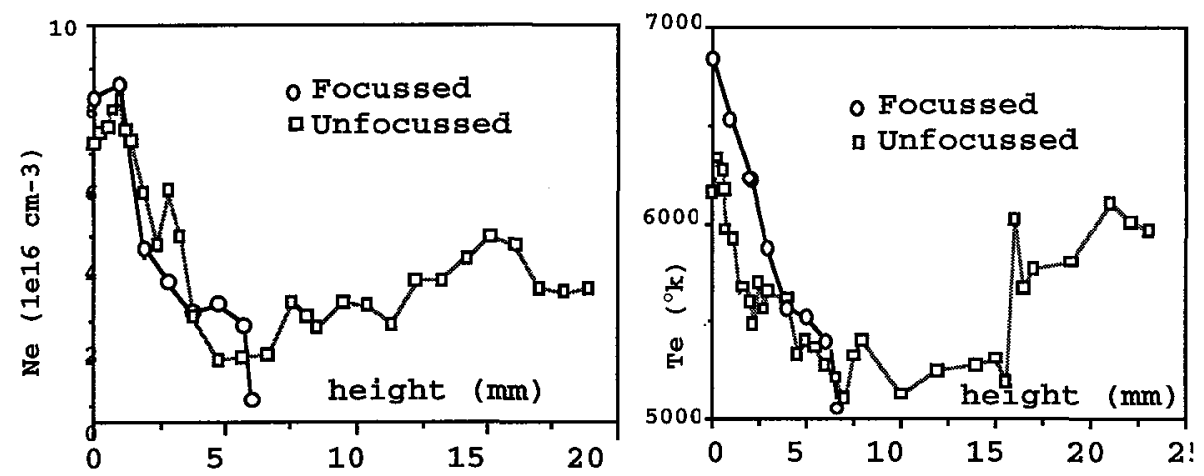

Fig. 1 : Electronic density and temperature profiles along the plasma plume. Diameter of focal spots of 0.7 and $3 \mathrm{~mm}$; Incident power $16 \mathrm{~kW} ; \mathrm{V}=20 \mathrm{~mm} / \mathrm{s}$.

Typical electronic densities and temperature are $10^{17} \mathrm{~cm}-3$ and $0.6 \mathrm{eV}$. In these experimental conditions, and using these data and the I. B. absorption coefficient defined by (2), the plasma plume transmission can be estimated about 75 to $90 \%$. It means that the plasma is rather transparent when $\mathrm{He}$ is used. One can verify these indirect determination of plume transmitivity by measuring target reflectivity with integrating sphere techniques $\{4\}$.

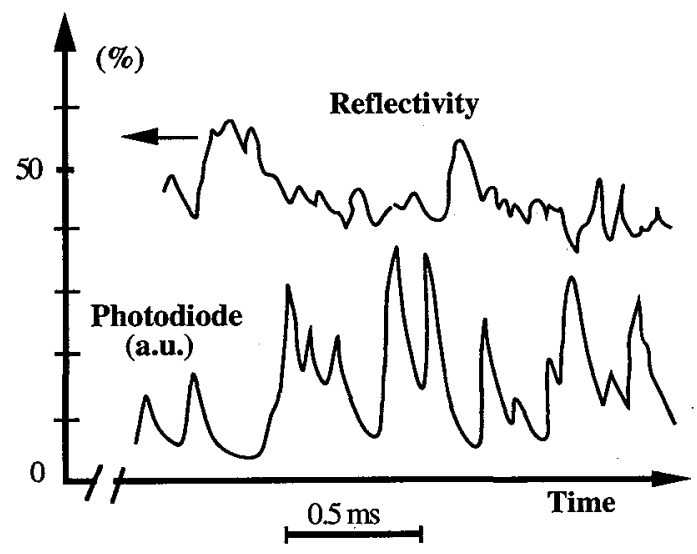

Fig. 2 : Cross-correlations between fluctuations of reflectivity (measured by the integrating sphere technique) and plasma luminosity (measured with visible range photodiodes).

Figure 2 shows the cross-correlations between the plasma luminosity and target reflectivity for He shielding gas : a high visible luminosity means a large plasma plume and is associated with a decrease in reflectivity. With argon shielding gas, at high 
intensity, the behaviour is very different : a plasma plume, only composed of argon ions, is detached from the target surface and oscillates with a frequency which is mainly function of focusing conditions (fig . 3).

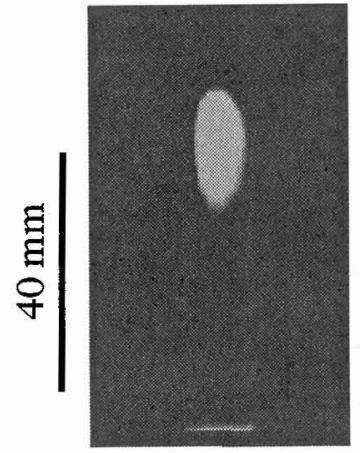

ARGON

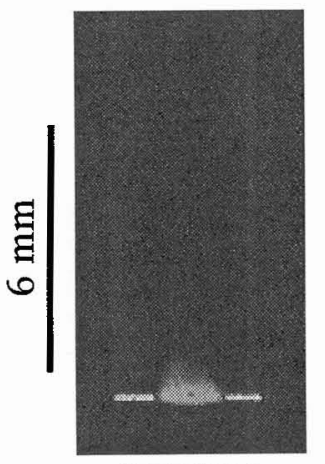

HELIUM
Fig. 3 : Plasma luminosity for He and $\mathrm{Ar}$ shielding gas. Incident Power 15 $\mathrm{kW}$; Frame camera : 2000 image/s.

Moreover in these conditions, no keyhole is present. Similar spectroscopic measurements show that the plume transmission has to be about 35 to $40 \%$ and this result is also in agreement with direct reflectivity measurements. The transmitivity being rather high and no keyhole being present, means that strong defocussing occurs during the beam propagation accross the plasma.

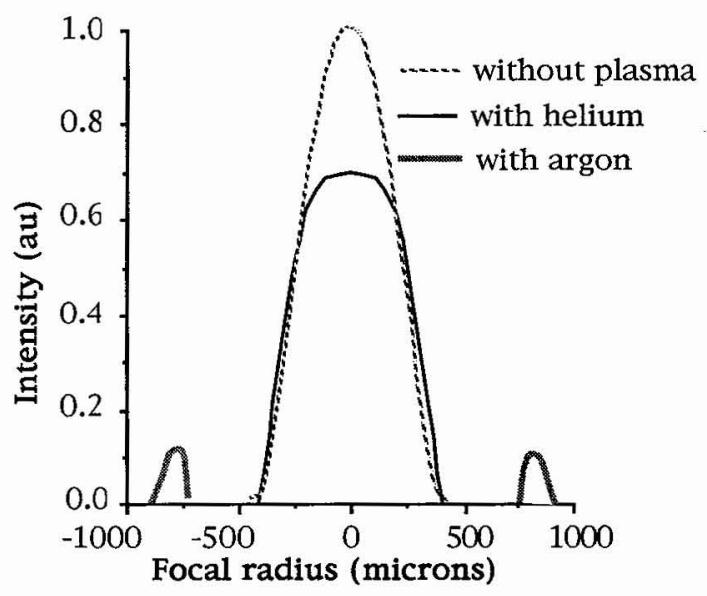

Fig. 4 : Computed intensity distribution due to refraction effects with plasmas obtained under $\mathrm{He}$ or $\mathrm{Ar}$ shielding gas. Realistic 2-D profiles of electronic density defined from experimental results have been used. The He plasma is localised at the target surface and the Ar one is detached of $30 \mathrm{~mm}$ from the surface.

Initial gaussian focal spot diameter of $0.5 \mathrm{~mm}$.

We have computed this refraction effects for these 2 characteristic plasmas with He and Ar shielding gas. Fig. 4 shows the perturbation of an initial focal spot of $0.5 \mathrm{~mm}$ of diameter (F. W. H. M.) for these 2 cases : For He, the laser intensity distribution is slightly modified. On the opposite with argon, the maximum intensity is decreased by one order of magnitude due to the defocussing resulting of the detached plasma.

3) Experiments under modified ambiant pressure.

In order to decrease the electronic density and therefore the perturbing associated effects, these experiments have been reproduced in a vacuum chamber where the ambiant pressure could be varied down to few torrs. The corresponding variations of the electronic density and temperature have been reported on fig. 5-a. With the hypothesis that the pressure of the plasma is given by the ambiant pressure, we can compare the electronic densities determined experimentally and those computed using 
Saha equation describing the ionisation of the medium and taking into account the experimental temperature (fig. 5-b).
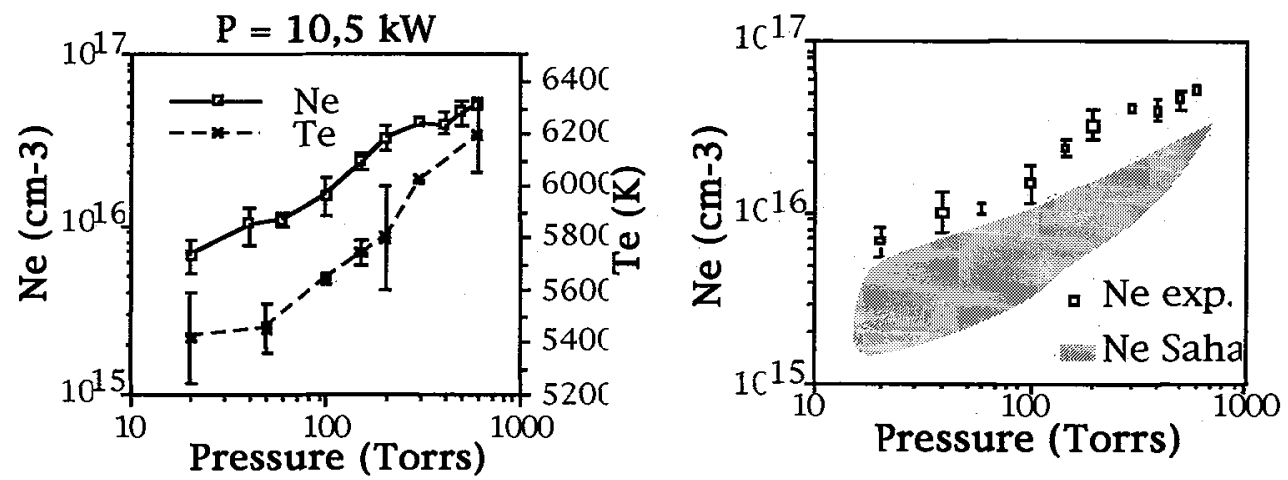

Fig. 5: a) Variation of the mean electronic density and temperature as a function of the He pressure in the vacuum chamber.

b) Comparison between computed Saha equation and experimentally measured electronic density.

The rather good agreement validates this hypothesis. This means that the electronic density of the plume is controlled by the ambiant pressure. Inside the keyhole, the electronic density is also controlled by the ambiant pressure, because the outgoing flow is subsonic. Therefore, the energy deposition law inside the keyhole has to be strongly modified by changing the ambiant pressure.

Effectively, one can see (fig. 6), at low welding velocities, that the penetration depths greatly increase when the ambiant pressure decreases. This means that the plasma absorption processes are strongly reduced in these conditions.

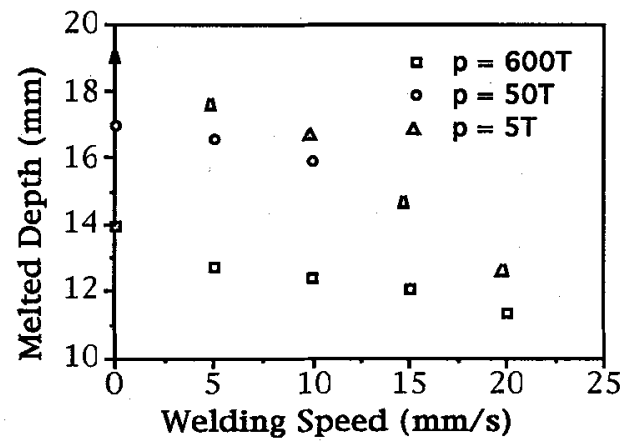

Fig. 6 : Variation of the penetration depths as a function of the welding speed and ambiant He pressure $(\mathrm{Pabs}=7.5 \mathrm{~kW})$.

Also, the bed-cross sections show interesting modifications (fig. 7). The bed cross section of the melted zone is strongly affected : at low pressure, its shape becomes regular indicating a uniform energy depostion law. 

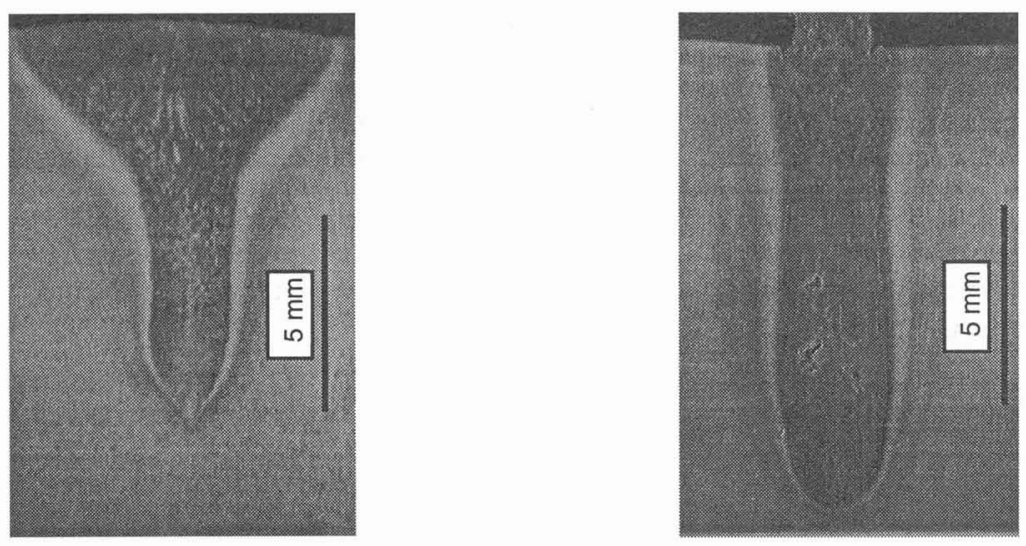

Fig. 7 : Examples of bed-cross sections for He ambiant pressures of 600 and 5 torrs (Pabs $=7.5 \mathrm{~kW}, \mathrm{~V}=10 \mathrm{~mm} / \mathrm{s}$ ).

In order to analyse these bed cross sections, we have made simulations of the thermal processes occuring inside the metallic target. Several hypothesis have been used in order to model the thermal effects issued from the keyhole. The local tilt of the stationary shape of the keyhole is defined as a function of the ratio of the welding velocity and of the drilling velocity which which is proportionnal to the local intensity. This drilling velocity has been measured otherwise and is typically of the order of $50 \mathrm{~cm} / \mathrm{s}$. The line deposition energy along the keyhole (defined by an absorption coefficient) is then ajusted in order to reproduce the experimental fusion isotherms. Fig. 8 shows examples of this adjustment.
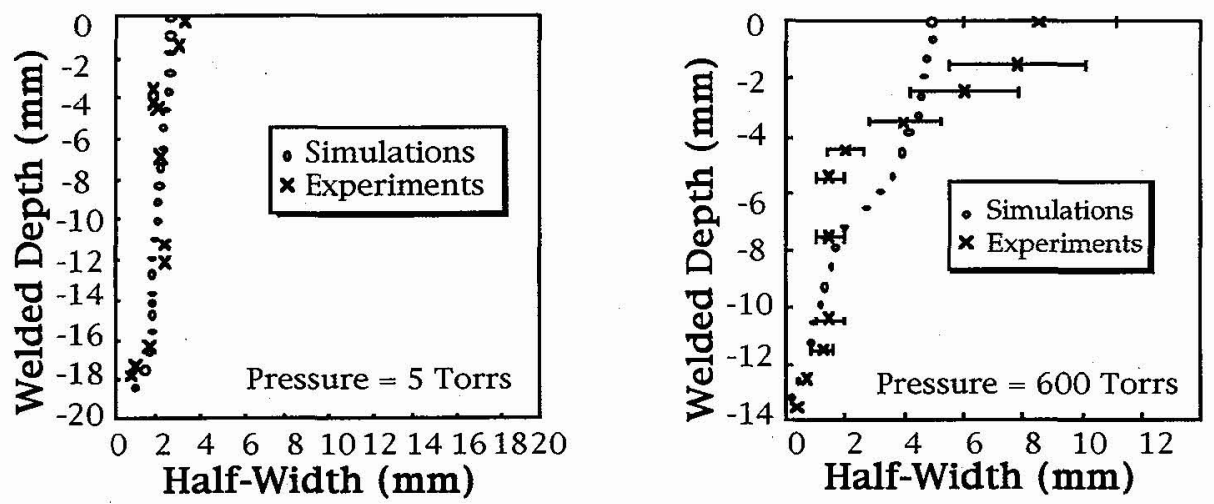

Fig. 8 : Determination of the energy deposition law by comparison between computed and experimentally determined bed cross sections for 2 ambiant pressures.

Typically, we observe that the absorption coefficient $\beta$ inside the keyhole at low pressures (about 5 torrs) is about $0.5-0.6 \mathrm{~cm}^{-1}$ and it increases linearly with the welding velocity. At this pressure, we have seen that no more plasma is present inside the keyhole, therefore this absorption coefficient is only related to the Fresnel reflexion mechanism. At atmospheric pressure, when plasma is present, the coefficient $\beta$ increases to about $1.7-1.8 \mathrm{~cm}^{-1}$. These values have been confirmed by measuring directly the power transmitted through metallic foils of different thicknesses. As a 
consequence, the absorption of the plasma alone can be determined and is simply given by the difference between these 2 values, which is typically about $1.2 \mathrm{~cm}^{-1}$.

Moreover, as we have seen in section 2, this value is about 2 times greater than in the outside plasma plume : as the absorption coefficient scales with the square of the electronic density, these measurements show that the electronic density inside the keyhole is about $40 \%$ greater than in the plasma plume. In these conditions with a $\mathrm{CO}_{2}$ laser, we can conclude that for these rather low welding velocities, the main limiting process for deep penetration comes from I. B. mechanism in the plasma. It shows also that the lowest absorption coefficient in the keyhole which can be obtained in these conditions is defined by Fresnel effects and is about $0.5 \mathrm{~cm}^{-1}$.

\section{4) Conclusion.}

These results show that the main perturbating processes for deep penetration are I. B. absorption, refraction and breakdown phenomena. All these processes show a strong $\lambda^{2}$ scaling with the wavelenght. Therefore they will be efficiently reduced by using shorter wavelenghts than the $\mathrm{CO}_{2}$ one, for example at $1.06 \mu \mathrm{m}$. Shorter wavelenght could be useful, but an optimum has to exist because it is known that Fresnel absorption increases with this trend. A possible way for decreasing these perturbing effects is to decrease the mean electronic density of the plasma. We have seen that vacuum welding is one possibility, but this method has of course no industrial interest. An other proposed method $\{6\}$, is to used electronegative gases, such as SF6, but the efficiency of this method seems very low. One can also use repetitive pulse processing, with pulse durations shorter than the plasma breakdown time (as defined in section 1). Some preliminary studies seem to confirm this possibility $\{7\}$, and the remarquable performances of a new type of $\mathrm{CO}_{2}$ lasers $\{8\}$, result of this concept. Also a high speed blowing of the plasma plume seems to be an easy way of action and should be more studied for suppression of the refraction processes.

Therefore several possibilities exist for improving this welding process. It is clear that only fundamental studies will provide better choice of the processing parameters in order to make this rather complex process more reliable and which needs for this purpose, for example real time control devices for constant efficiency as required for industrial environment. We have discussed here phenomena related to plasma effects ; if one wants to really achieve a complete understanding of this process it seems obvious that similar approach has to be defined for other aspects of this process, as for example the hydrodynamic behaviour of the melt pool and its effects on porosities or microstructure, and as a final result, on mechanical resistance of the welded joint.

\section{REFERENCES :}

$\{1\}$ G. Herziger, "Basic Elements of LaserMaterial Processing," Proceedings of SPIE, Vol. 455, (1983), pp. 66-74

\{2\} A.I. Barchukov, F.V. Bunkin, V.I. Konov and A.A. Lyubin, Soviet Physics JETP, 39, 469 (1974)

\{3\} A. Poueyo,G. Deshors, R. Fabbro, A. M. de Frutos and J.M. Orza : "Study of Laser induced plasma in Welding Conditions with Continuous High Power $\mathrm{CO}_{2}$ Lasers," proceedings de la Conférence LAMP, Nagaoka, p. 323,1992.

$\{4\}$ R. Fabbro, D. Bermejo, J. M. Orza, L. Sabatier, L. Leprince et V. Granier Proceedings of SPIE, Vol. 1276, P. 461 (1990)

$\{5\}$ A. Poueyo-Verwaerde, R. Fabbro, G. Deshors, A. M. de Frutos, J. M. Orza, J. Appl. Phys. 74, 5773 (1993).

$\{6\}$ E. Beyer, K. Behler and G. Herziger, Proceedings of SPIE, Vol. 1020, (1988), pp. 84-85.

\{7\} T. Ishide, S. Shono, T. Ohmae, H. Yoshida and A. Shinmi, Proceeding of LAMP Conference, Osaka, (1987), pp. 187-191.

$\{8\}$ "Diamond" series from Coherent 